\title{
Differential effect of angiotensin II and blood pressure on hippocampal inflammation in mice
}

M. Florencia Iulita ${ }^{1,2}$, Diane Vallerand ${ }^{3}$, Mélissa Beauvillier ${ }^{3}$, Nathalie Haupert $^{3}$, Corinne A. Ulysse ${ }^{3}$, Audrey Gagné $^{4}$, Nathalie Vernoux ${ }^{4}$, Sonia Duchemin ${ }^{3}$, Michaël Boily ${ }^{3}$, Marie-Ėve Tremblay ${ }^{4,5}$ and Hélène Girouard ${ }^{2,3,6^{*}}$ (D)

\begin{abstract}
Background: Angiotensin II (Ang II), a peptide hormone involved in the development of hypertension, causes systemic and cerebral inflammation, affecting brain regions important for blood pressure control. The cause-andeffect relationship between hypertension and inflammation is two-way, but the role of blood pressure in the induction of cerebral inflammation is less clear. The vulnerability of specific brain regions, particularly those important for memory, is also of interest.

Methods: We used molecular biology approaches, immunohistochemistry, and electron microscopy to examine the interdependence between the hypertensive and pro-inflammatory effects of Ang II. We examined the effect of blood pressure by administering a subpressive (200 $\mathrm{ng} / \mathrm{kg} / \mathrm{min})$ or a pressive Ang II dose (1000 or $1900 \mathrm{ng} / \mathrm{kg} / \mathrm{min}$ ) with and without hydralazine $(150 \mathrm{mg} / \mathrm{L})$ for 1 week and used phenylephrine to increase blood pressure independently of the renin-angiotensin system.
\end{abstract}

Results: Ang II increased ionized calcium-binding adaptor molecule 1 (Iba-1) levels (marker of microgliosis) in the whole brain and in the hippocampus in a dose-dependent manner. Pressive Ang II induced specific changes in microglial morphology, indicating differences in functional phenotype. An increase in hippocampal glial fibrillary acidic protein (GFAP) was seen in mice receiving pressive Ang II, while no induction of cerebral gliosis was observed after 7 days of subpressive Ang II infusion. Although phenylephrine led to increased astrogliosis, it did not affect Iba-1 expression. Pressive Ang II stimulated TNF-a production in the hippocampus, and daily treatment with hydralazine prevented this increase. Hydralazine also reduced GFAP and Iba-1 levels. With longer perfusion (14 days), subpressive Ang II led to some but not all the inflammatory changes detected with the pressive doses, mainly an increase in CD68 and Iba-1 but not of GFAP or TNF-a.

Conclusions: Blood pressure and Ang II differentially contribute to hippocampal inflammation in mice. Control of blood pressure and Ang II levels should prevent or reduce brain inflammation and therefore brain dysfunctions associated with hypertension.

Keywords: Angiotensin II, Hypertension, Inflammation, Blood pressure, Microglia, TNF-a, GFAP, Iba-1, Hydralazine

\footnotetext{
* Correspondence: helene.girouard@umontreal.ca

${ }^{2}$ Groupe de recherche sur le système nerveux central (GRSNC), Université de

Montréal, 2960 Chemin de la Tour, Montréal, Québec H3T 1J4, Canada

${ }^{3}$ Department of Pharmacology and Physiology, Université de Montréal,

Pavillon Roger-Gaudry, 2900 Boulevard Édouard-Montpetit, Montréal, Québec

H3T 1J4, Canada

${ }^{6}$ Centre de recherche de l'Institut universitaire de gériatrie de Montréal, 545

Queen Mary Rd, Montréal, Québec H3W 1W6, Canada

Full list of author information is available at the end of the article
}

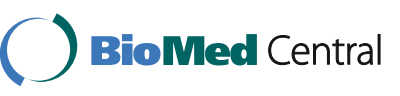

(c) The Author(s). 2018 Open Access This article is distributed under the terms of the Creative Commons Attribution 4.0 International License (http://creativecommons.org/licenses/by/4.0/), which permits unrestricted use, distribution, and reproduction in any medium, provided you give appropriate credit to the original author(s) and the source, provide a link to the Creative Commons license, and indicate if changes were made. The Creative Commons Public Domain Dedication waiver (http://creativecommons.org/publicdomain/zero/1.0/) applies to the data made available in this article, unless otherwise stated. 


\section{Background}

Hypertension is a serious public health issue, being highly prevalent in the elderly [1] and a leading risk factor for stroke [2], cognitive impairment, and dementia [3]. Despite the vast array of drugs to lower blood pressure, hypertension control remains suboptimal stressing the need for better therapeutic management.

Besides reflecting an increase in arterial blood pressure, hypertension consists of a chronic, low-grade inflammation involving innate and adaptive immune cells [4]. The link between systemic inflammation and high blood pressure has been well described by human [5-7] and animal data [8-14]. However, the effects of hypertension on the pathogenesis of cerebral inflammation are less understood.

Studies examining the role of cerebral inflammation in experimental hypertension have focused on the paraventricular nucleus (PVN), a region of the hypothalamus involved in the sympathetic control of blood pressure [15]. Using anti-inflammatory approaches (with minocycline or IL-10 administered directly to the brain) or depleting microglia by intra-cerebro-ventricular administration of diphtheria toxin (DT) to transgenic CD11b-DT receptor mice, these studies have shown that inflammation and microglia play a central role in the development of high blood pressure in mice and rats $[16,17]$. While finding that inflammation influenced blood pressure, they also showed that hypertension, which was achieved via systemic infusion of angiotensin II (Ang II), was capable of producing increases in microglial density, soma enlargement, and reductions in microglial process length, as well as greater production of pro-inflammatory cytokines (IL-1 $\beta$, IL-6, and TNF- $\alpha$ ) in this brain region [16-18].

Given the strong associations between mid-life hypertension and late-life dementia [19-21], the involvement of other vulnerable brain structures such as the hippocampus, a key region involved in memory formation, is also of significant interest. Likewise, whether the cerebral inflammatory effects of circulating Ang II are a consequence of its own cellular actions only, whether they are mediated by its increase in blood pressure, or whether blood pressure itself can do so independently of Ang II remains unclear.

Therefore, this study was set to answer these questions. We administered Ang II in the systemic circulation of C57BL/6 mice during 7 or 14 days and examined the inflammatory response in the whole brain and in the hippocampus using a multidisciplinary approach. In order to dissect the effects of Ang II and blood pressure, we delivered pressive versus subpressive Ang II doses and phenylephrine, or used the peripheral vasodilator hydralazine to prevent hypertension. Our results show that Ang II and blood pressure can differentially contribute to the development of hippocampal inflammation in mice.

\section{Methods \\ Animals}

Ten to 12-week-old male C57BL/6 mice (Charles River Laboratories, Saint-Constant, Canada) were housed individually in a temperature-controlled room with a 12-h light-dark cycle and access to food and water ad libitum. Following acclimatization, mice were randomly assigned to experimental groups. The precise number of animals used for each experiment is specified in the Results section and in the figure legends.

Osmotic minipump implantation and hydralazine treatment Alzet osmotic minipumps (model 1007D, Durect Corporation, Cupertino, USA) were subcutaneously implanted as previously described [22]. Mice received bupivacaine hydrochloride (Marcaine, CDMV, Canada, $2 \mathrm{mg} / \mathrm{kg}$ s.c.) at the site of the incision before and after minipump implantation. Each pump delivered 200 or $1000 \mathrm{ng} / \mathrm{kg} /$ min of Ang II (Millipore-Sigma, Maine, USA) at a rate of $0.5 \mu \mathrm{L} / \mathrm{h}$ during 7 days. Saline $(0.9 \%)$ was used for the control groups. For ionized calcium-binding adaptor molecule 1 (Iba-1) and glial fibrillary acidic protein (GFAP) analysis, an additional group of mice was included receiving either Ang II $1900 \mathrm{ng} / \mathrm{kg} / \mathrm{min}$ or phenylephrine $(19 \mu \mathrm{g} / \mathrm{kg} / \mathrm{min})$. Phenylephrine (Sigma-Aldrich, Oakville, Canada) was infused via osmotic minipumps, in the same conditions. A separate group of mice was implanted with minipumps that delivered the subpressive Ang II dose during 14 days (model 1002, rate $0.25 \mu \mathrm{L} / \mathrm{h}$, Durect Corporation, Cupertino, USA). For hydralazine treatment (Hyd), mice were divided into four groups: mice receiving regular drinking water (control and Ang II $1000 \mathrm{ng} / \mathrm{kg} / \mathrm{min}$ ) and mice receiving $150 \mathrm{mg} / \mathrm{L}$ of hydralazine hydrochloride (Sigma-Aldrich, Oakville, Canada) daily in the drinking water (control + Hyd and Ang II + Hyd groups). Hydralazine treatment started 3 days before the minipump implantation and continued during the 7 days of Ang II perfusion. The hydralazine solution was replaced each day. The optimal concentration of hydralazine was chosen based on a pilot study. For a positive control of systemic inflammation, mice were intraperitoneally (i.p.) injected with a single dose of lipopolysaccharides (LPS from Escherichia coli, $2 \mathrm{mg} / \mathrm{kg}$, Sigma-Aldrich, Oakville, Canada) and sacrificed $3 \mathrm{~h}$ later.

\section{Blood pressure measurement}

Blood pressure was monitored by non-invasive tail-cuff plethysmography (Kent Scientific Corporation, Torrington, USA). Blood pressure assessment began 3 days before minipump implantation in order to habituate the mice to the procedure and continued at three different 
intervals (days 0,4 , and 7) during 1 week. Mice were placed on a heating platform for $10 \mathrm{~min}$ before assessment of blood pressure. A minimum of five measurements were taken until the blood pressure stabilized and, following stabilization, a minimum of eight measurements were taken per mouse and averaged for analysis. Blood pressure was monitored by the same person at the same time of the day.

\section{Western blotting}

Equal amounts of proteins from whole brain homogenates $(75 \mu \mathrm{g})$ were subjected to electrophoresis and transferred to nitrocellulose membranes (BioRad, ON, Canada). Membranes were probed with rabbit anti-Iba-1 (1:500, Wako Inc., Richmond, USA) or mouse antiGFAP (1:2000, Millipore-Sigma, Maine, USA) antibodies overnight at $4{ }^{\circ} \mathrm{C}$. Rabbit anti-pan actin (1:1000, New England Biolabs, Ltd., Whitby, Canada) was used as loading control. Densitometric analysis was performed using ImageJ software (National Institutes of Health, Bethesda, USA), and the ratio Iba-1/actin or GFAP/actin was expressed relative to the control group. Details on tissue preparation and additional details on the Western blot protocol are available in Additional file 1: Supplementary Methods.

\section{RNA extraction and quantitative real-time PCR (qRT-PCR)}

Details on tissue preparation are available in Additional file 1: Supplementary Methods. Hippocampal RNA was extracted with the RNeasy Plus kit (Qiagen, Toronto, Canada) and retrotranscribed with the qScript cDNA Supermix Quanta kit (VWR, Mississauga, Canada). In preliminary experiments, three different sets of Iba-1 primers were tested; however, due to lack of specific amplification, we resorted to measure CD68, a marker of phagocytic microglia. For all PCR reactions, $500 \mathrm{nM}$ (GFAP and CD68) and $300 \mathrm{nM}$ (GUSB) of the forward and reverse primers were used. The PCR protocol and primer sequences are detailed in Additional file 1: Supplementary Methods.

\section{Immunofluorescence}

Details on tissue preparation are available in Additional file 1: Supplementary Methods. Microglia were labeled with rat anti-mouse CD68 (1:10,000, AbDSerotec, Bio-Rad Laboratories, USA) or rabbit anti-Iba-1 (1:1000, Wako Inc., Richmond, USA) and astrocytes with mouse anti-GFAP primary antibodies (1:500, Invitrogen-Thermo Fisher Scientific, Burlington, Canada) as detailed in Additional file 1: Supplementary Methods. To minimize immunolabeling variations, sections from all groups in each batch were processed together. Immunolabeling specificity was assessed by omitting the primary antibodies. Confocal images were acquired with an Olympus laser-scanning microscope (model FV1000MPE). Two images per region per brain section, for a total of three sections per mouse, were captured for each condition. Expression levels of the markers of interest were analyzed in the hippocampal regions cornu ammonis 1 (CA1), cornu ammonis 3 (CA3), and dentate gyrus (DG) (from Bregma - 1.46 to $1.70 \mathrm{~mm}$ ), following previously published protocols [23]. Confocal images were imported into ImageJ (National Institutes of Health, Bethesda, USA), and the mean gray value tool was used to calculate relative fluorescence intensity units (RFU) in manually designed regions of interest (polygons of size 9.8E-5), computing an average RFU per section. Values were expressed relative to control group after background subtraction.

\section{Tissue processing for electron microscopy and ultrastructural analysis}

Immunostaining was performed on sections containing the dorsal hippocampus (from Bregma - 1.46 to $1.55 \mathrm{~mm}$ ). Details on tissue processing and staining are available in the Additional file 1: Supplementary Methods. Pictures of Iba-1-stained microglial cell bodies and processes were randomly captured in the DG polymorphic layer at a magnification of $\times 6800$ using an ORCA-HR bottom-mount digital camera (10 MP; Hamamatsu). For unbiased quantitative analysis, $\sim 75$ Iba-1-positive microglial processes per animal were analyzed by an observer blinded to the experimental conditions using ImageJ (National Institutes of Health, Bethesda, USA). The area, perimeter, and shape descriptor measurements circularity and solidity were used to assess changes in morphology. Vacuoles associated with autophagy and phagocytosis were also counted on a microglial process basis. In addition, the proportion of microglial processes associated with pockets of extracellular space containing cellular debris showing signs of digestion (i.e., shrinkage and increased width of the associated extracellular space), termed "extracellular digestion," was determined.

\section{TNF- $\alpha$ and IL-6 ELISA}

TNF- $\alpha$ and IL- 6 were assessed by ELISA (mouse TNF- $\alpha$ kit \#KMC3011 and mouse IL-6 kit \#KMC0061, InvitrogenThermo Fisher Scientific, Burlington, Canada) in the brain or hippocampal homogenates as well as in plasma samples, as described in Additional file 1: Supplementary Methods. In order to combine data measured from separate kits, results were expressed as fold change with respect to the control group.

\section{Statistical analysis}

Data analysis was done with GraphPad Prism v.7.0 (La Jolla, USA). Multiple group comparisons were evaluated by one-way or two-way analysis of variance (ANOVA), with the Tukey post hoc test. Two-group comparisons were analyzed with the Mann-Whitney test or a two- 
tailed $t$ test, as appropriate. Spearman rank correlation was used to examine the association between TNF- $\alpha$ and blood pressure. A value of $p \leq 0.05$ was considered statistically significant. For each experiment, the statistical analysis is specified in the figure legends and tables. Data is presented as mean \pm SEM.

\section{Results}

\section{Effect of Ang II doses on blood pressure}

Subcutaneous perfusion of Ang II at a concentration of $1000 \mathrm{ng} / \mathrm{kg} / \mathrm{min}$ resulted in a steady significant increase in systolic blood pressure (SBP) of $33.8 \mathrm{mmHg}$ (mean increase) at day 4 and $37.1 \mathrm{mmHg}$ (mean increase) at day 7 , compared to day 0 (Table 1 ). In these conditions, a dose of Ang II of $200 \mathrm{ng} / \mathrm{kg} / \mathrm{min}$ did not increase SBP even after 7 days of continued perfusion. The blood pressure of animals receiving Ang II 200 was also comparable to that of controls and will be therefore referred as subpressive. The blood pressure of animals receiving Ang II 1000 was greater than that of controls at days 4 and 7 and will be referred as pressive or hypertensive.

\section{Effect of Ang II on cerebral gliosis}

Mice receiving a hypertensive dose of Ang II exhibited greater levels of Iba-1 in the whole brain compared to controls $(p=0.035)$ or to mice receiving Ang II 200 ( $p=$ 0.034) (Fig. 1a, $n=9-12$ ), indicating either an increase in the number of microglia or phenotypical changes of these cells. GFAP protein levels followed a similar trend in response to pressive Ang II $(p=0.076$, Fig. $1 \mathrm{~b}, n=$ 14-15). No significant changes in cerebral gliosis were detected in mice receiving subpressive doses of Ang II after 7 days perfusion (Fig. 1).

In the hippocampus, Ang II infusion did not increase CD68 mRNA synthesis regardless of the dose (Fig. 2a, $n=4-5)$. Instead, a significant increase in GFAP mRNA expression was evident in mice that received the hypertensive dose of Ang II $(p=0.031)$ but not the subpressive dose (Fig. 2b, $n=4-5$ ). In line with the mRNA results, quantitative immunofluorescence showed

Table 1 Effect of Ang II doses on systolic blood pressure

\begin{tabular}{|c|c|c|c|}
\hline & Control & Ang $\| 200$ & Ang $\| 1000$ \\
\hline SBP day 0 & $132.0 \pm 3.0$ & $127.6 \pm 3.5$ & $125.3 \pm 4.4$ \\
\hline SBP day 4 & $132.1 \pm 3.9$ & $133.2 \pm 4.3$ & $159.1 \pm 9.5^{\text {sq }}$ \\
\hline SBP day 7 & $127.0 \pm 4.1$ & $129.0 \pm 4.8$ & $162.4 \pm 8.3^{8-}$ \\
\hline
\end{tabular}

Systolic blood pressure (SBP, $\mathrm{mmHg}$ ) was assessed via the tail-cuff method. Mice were implanted with osmotic minipumps containing Ang II 200 ng/kg/ min (referred as Ang II 200), Ang II $1000 \mathrm{ng} / \mathrm{kg} / \mathrm{min}$ (referred as Ang II 1000), or $0.9 \% \mathrm{NaCl}$ (referred as control). Data is expressed as mean $\pm \mathrm{SEM}, n=7-12$ / group; two-way ANOVA and Tukey post-test. Main effect of time $F(2,92)=$ $5.203, p<0.01$; main effect of treatment $F(2,92)=12.95 p<0.0001$; interaction $F(4,92)=5.372, p<0.001$

${ }^{\S} p<0.001$ Ang II 1000 day 4 and day 7 versus day 0 , " $p<0.05$ Ang II 1000 versus Ang II 200 and versus control, ${ }^{+} p<0.001$ Ang II 1000 versus Ang II 200 and versus control comparable hippocampal CD68 levels between mice receiving subpressive Ang II and their controls, although a trend revealing a mean $16 \%$ increase in CD68 was seen with the pressive dose ( $p=0.09$, Fig. $2 c, n=4-6)$. Iba- 1 showed a similar response (Fig. 2d, $n=4-6$ ). We then examined the impact of Ang II on hippocampal astrogliosis. Immunofluorescence analysis revealed a significant increase in GFAP levels of around 50\% in response to pressive Ang II $(p=0.001)$ but not to the subpressive dose (Fig. 2e).

To further distinguish the effects of Ang II and blood pressure on hippocampal gliosis, we used three different strategies. In the first one, we used a higher pressive Ang II dose (1900 ng/ $\mathrm{kg} / \mathrm{min})$ that increased blood pressure to the same level of the dose of $1000 \mathrm{ng} / \mathrm{kg} / \mathrm{min}$. The second one examined the effects of phenylephrine, a hypertensive drug which is Ang II-independent. The third prevented Ang II-induced hypertension by simultaneously treating mice with hydralazine.

Despite a similar increase of blood pressure as the dose of $1000 \mathrm{ng} / \mathrm{kg} / \mathrm{min}$ (Tables 1 and 2), infusion of a higher pressive Ang II concentration (1900 ng/ $\mathrm{kg} / \mathrm{min}$ ) led to a significant increase in hippocampal Iba-1 compared to controls $(p<0.0001$, Fig. 3a, $n=4-5)$, suggesting a dosedependent effect of Ang II on microgliosis. The higher dose of Ang II (1900 ng/ $/ \mathrm{kg} / \mathrm{min})$ also increased GFAP levels by $60 \%$ following the 7 -day chronic administration ( $p<0.0001$, Fig. 3b, $n=4-5)$.

No change in hippocampal Iba-1 expression was detected with perfusion of phenylephrine (Fig. 3a), even though it significantly raised blood pressure following the 7 days of chronic infusion (Table 2). Instead, phenylephrine significantly increased GFAP levels $(p<0.0001$, Fig. 3b, $n=4-5$ ), indicating that increased blood pressure alone can contribute to hippocampal astrogliosis.

With a different strategy to explore the effects of blood pressure, we looked at Iba-1 and GFAP levels in the hippocampus of mice receiving the hypertensive dose of Ang II (1000 ng/ $\mathrm{kg} / \mathrm{min})$ and treated with the peripheral vasodilator hydralazine (Fig. 4). Treatment with hydralazine effectively lowered blood pressure in hypertensive mice (Table 3 ). In line with earlier results quantitative immunofluorescence showed comparable hippocampal Iba-1 levels between mice receiving Ang II 1000 and their controls in this region (Fig. 4a). Treatment with hydralazine, which had no effect in control animals, resulted in a $25 \%$ reduction of Iba- 1 in mice receiving Ang II, compared to those receiving the vehicle ( $p=0.055$, Fig. 4a, $n=3-6$ ). Likewise, hydralazine reduced the elevation in hippocampal GFAP in mice receiving Ang II 1000 ( $p=0.012$, Fig. 4b, $n=6-8$ ) to levels comparable to controls, supporting the idea that increased blood pressure is an important contributor to Ang II-induced astrogliosis. 


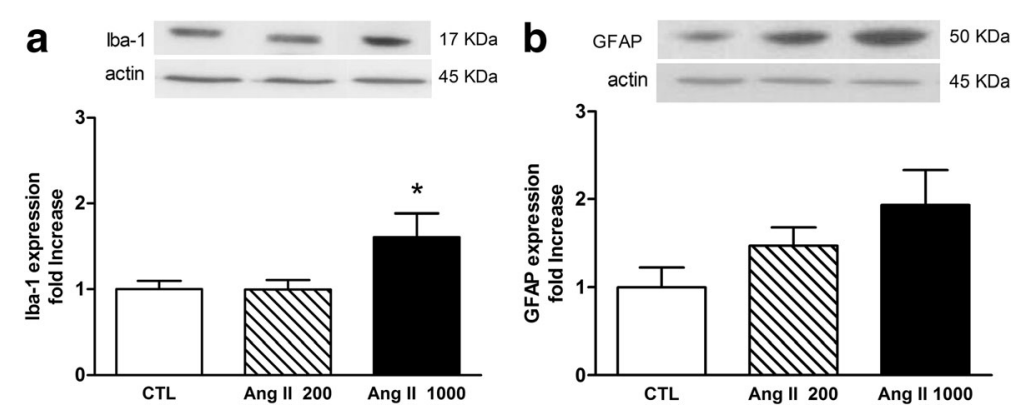

Fig. 1 Effect of Ang II on cerebral gliosis. Iba-1 (microglia/monocyte marker) (a) and GFAP (astrocytic marker) (b) were examined by Western blotting in cerebral homogenates after 1 week systemic perfusion of Ang II 200 or $1000 \mathrm{ng} / \mathrm{kg} / \mathrm{min}$ or $0.9 \%$ saline (CTL). Densitometry values of Iba-1 and GFAP were normalized to actin, and the results are expressed relative to the control group. Representative immunoblots are shown $\left({ }^{*} p<0.05\right.$ Ang II 1000 versus 200 or controls, by one-way ANOVA with Tukey post-test, $\left.n=9-15\right)$

To rule out that the absence of brain inflammatory changes in mice receiving the subpressive dose for 1 week was not due to insufficient perfusion time, we examined a separate group of mice that received chronic Ang II infusion (200 ng/kg/min) during 14 days. Western blot analysis in the whole brain revealed a trend for a mean $35 \%$ increase in Iba-1 levels $(p=0.065$,
Additional file 2: Figure S1A, $n=3$ ) and no differences in GFAP (Additional file 2: Figure S1B, $n=3$ ). While no differences in hippocampal CD68 had been seen with infusion of subpressive Ang II for 1 week, increasing Ang II perfusion to 2 weeks led to a significant rise in CD68 mRNA (mean increase 27\%, $p=0.0090$, Additional file 2: Figure S1C, $n=7$ ) and to a similar

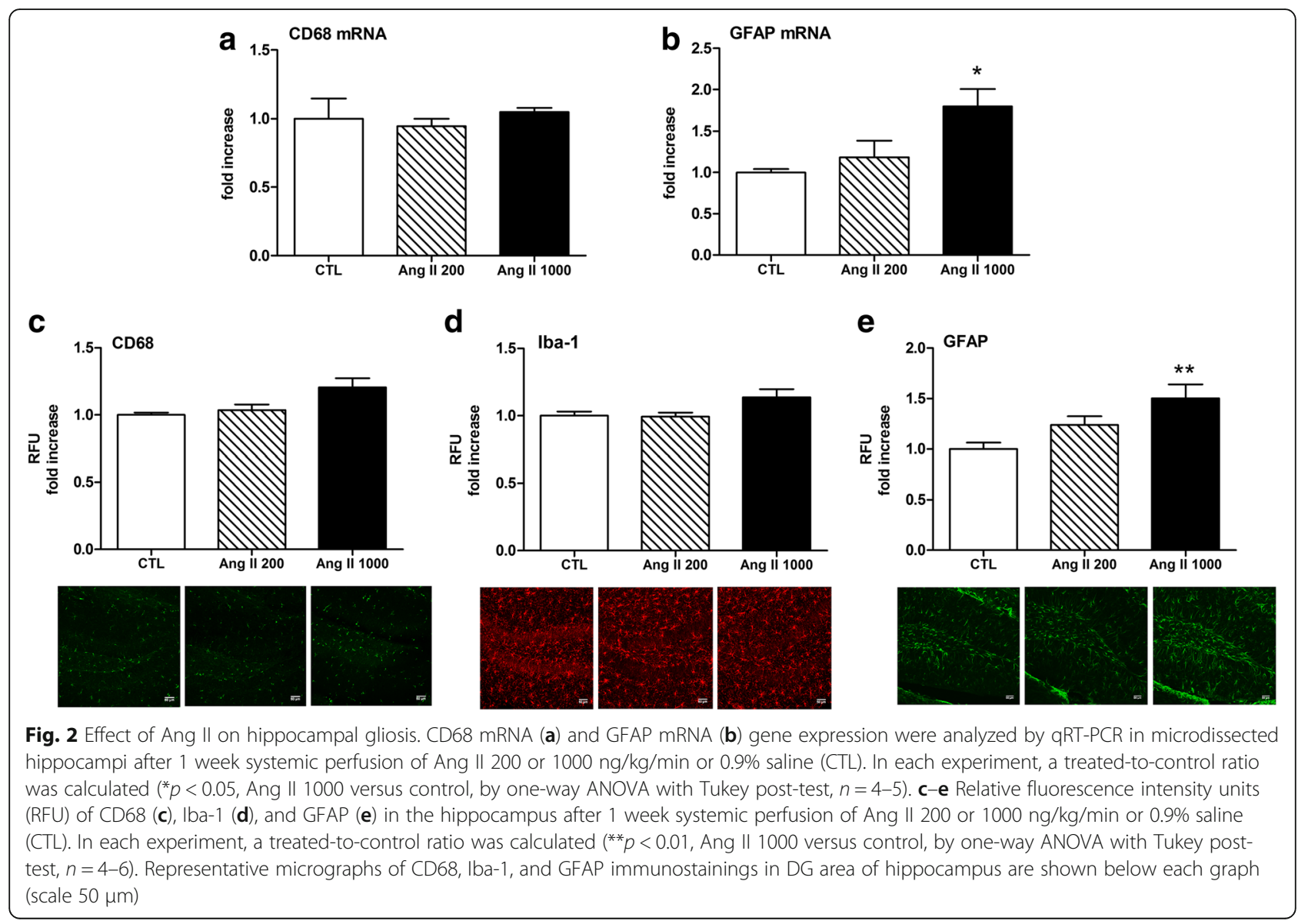


Table 2 Effect of Ang II and phenylephrine on systolic blood pressure

\begin{tabular}{llll}
\hline & Control & Phenylephrine & Ang || 1900 \\
\hline SBP day 0 & $131.9 \pm 3.2$ & $132.3 \pm 3.2$ & $135.7 \pm 1.0$ \\
SBP day 4 & $131.7 \pm 2.2$ & $142.5 \pm 5.7^{*}$ & $158.5 \pm 1.5^{\text {§q }}$ \\
SBP day 7 & $128.9 \pm 0.5$ & $145.6 \pm 2.1^{* \#}$ & $164.9 \pm 2.3^{\text {§+ }}$
\end{tabular}

Systolic blood pressure (SBP, $\mathrm{mmHg}$ ) was assessed via the tail-cuff method. Mice were implanted with osmotic minipumps containing phenylephrine $19 \mu \mathrm{g} / \mathrm{kg} / \mathrm{min}$, Ang II $1900 \mathrm{ng} / \mathrm{kg} / \mathrm{min}$ (referred as Ang II 1900), or $0.9 \% \mathrm{NaCl}$ (referred as control). Data is expressed as mean \pm SEM, $n=3$ /group; two-way ANOVA and Tukey post-test. Main effect of time $F(2,12)=15.64, p=0.0005$; main effect of treatment $F(2,6)=73.5 p<0.0001$; interaction $F(4,12)=7.252, p=0.003 .3$

" $p<0.01$ phenylephrine day 4 and day 7 versus control; ${ }^{*} p<0.05$ phenylephrine day 7 versus day $0 ;{ }^{5} p<0.001$ Ang II 1900 day 4 and day 7 versus day 0 ; $p<0.01$ Ang II 1900 versus phenylephrine and versus control; ${ }^{+} p<0.001$ Ang II 1900 versus phenylephrine and versus control

increase in GFAP mRNA (mean increase 29\%), although this difference did not reach statistical significance ( $p=0.117$, Additional file 2: Figure S1D, $n=7$ ).

\section{Effect of hypertensive Ang II on microglial morphology}

To better characterize the impact of hypertensive Ang II on cerebral gliosis, we performed a detailed quantitative analysis of microglial morphology in the hippocampus using immuno electron microscopy (EM). We studied ultrastructural changes in microglial processes (area, perimeter, circularity, and solidity) as well as changes in their accumulation of vacuoles and extracellular digestion. EM analysis showed significant differences in microglia morphology between control and hypertensive mice receiving Ang II $1000 \mathrm{ng} / \mathrm{kg} / \mathrm{min}(n=3-4)$. There was a $19 \%$ mean increase in both process area $(p=0.002$, Fig. 5a) and perimeter ( $p=0.0002$, Fig. $5 \mathrm{~b})$, indicating that processes are larger ("thickened") in the presence of Ang II. We also observed significant reductions in circularity ( $p=0.0005$, Fig. $5 c)$, indicating that processes have more complex shapes in the presence of pressive Ang II. Solidity, a measure of the indentations on the membrane of processes, was also reduced in animals infused with hypertensive Ang II ( $p=0.011$, Fig. $5 \mathrm{~d})$, indicating that microglia are more ruffled. This could be an indicator of increased motility. Electron microscopy also revealed significant increases in the abundance of microglial vacuoles (mean increase $72 \%, p=0.046$, Fig. 5e), indicating the occurrence of autophagy or phagocytic degradation and increased extracellular digestion in Ang II-infused mice (mean increase $112 \%, p<0.0001$, Fig. 5f).

\section{Effect of Ang II on cerebral pro-inflammatory cytokine production}

We next examined whether systemic Ang II would lead to increased production of pro-inflammatory cytokines in the brain. First, we confirmed that Ang II infusion increased the levels of the pro-inflammatory mediators TNF- $\alpha$ and IL-6 in plasma. As shown in Fig. 6a, b, hypertensive doses of Ang II led to significant increases in the circulating levels of TNF- $\alpha$ ( $p=0.022$ versus control and $p=0.067$ versus Ang II 200, $n=6$ ) and IL-6 $(p=0.004$ versus control and $p=0.003$ versus Ang II 200, $n=6-8)$. Mice that received Ang II $200 \mathrm{ng} / \mathrm{kg} / \mathrm{min}$
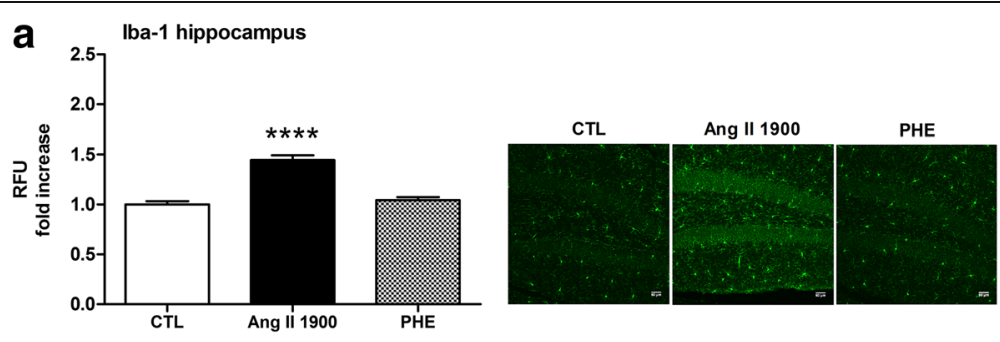

b
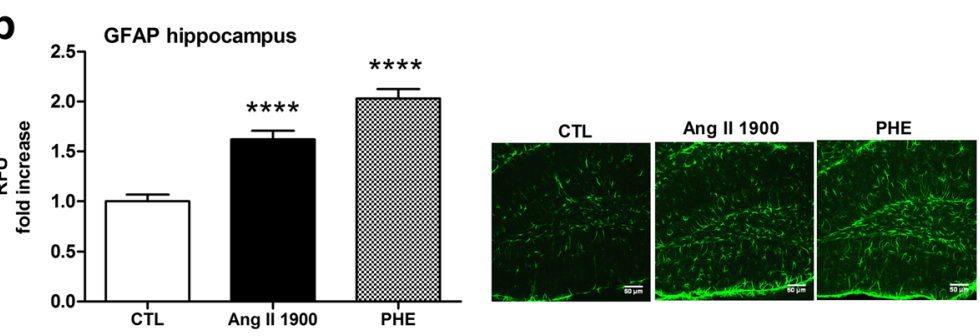

Fig. 3 Effect of Ang II and phenylephrine on hippocampal gliosis. Iba-1 (a) and GFAP (b) were examined by immunofluorescence in the hippocampus after 1 week systemic perfusion of Ang II 1900 ng/kg/min or phenylephrine (PHE) 19 mg/kg/min or 0.9\% saline (CTL). In each experiment, a treated-tocontrol ratio was calculated (**** $p<0.0001$, Ang II 1900 or PHE versus control, by one-way ANOVA with Tukey post-test, $n=4-5$ ). Representative micrographs of Iba-1 and GFAP immunostainings in the DG area of the hippocampus are shown (scale $50 \mu \mathrm{m}$ ). RFU: relative fluorescence intensity units 

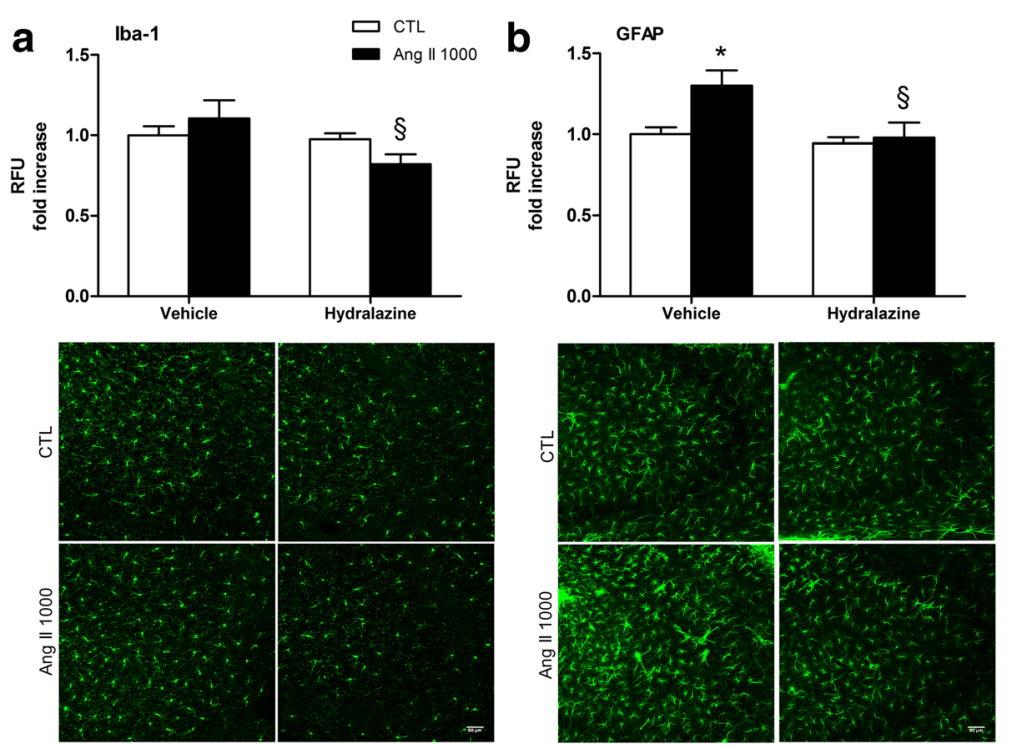

Fig. 4 Effect of hydralazine on hippocampal gliosis induced by Ang II. Relative fluorescence intensity units (RFU) of Iba-1 (a) and GFAP (b) in the hippocampus after 1 week systemic perfusion of Ang $\| 1000 \mathrm{ng} / \mathrm{kg} / \mathrm{min}$ or $0.9 \%$ saline (CTL). Hydralazine (150 mg/L) was administered in the drinking water starting 3 days before minipump implantation. Animals in the vehicle group received regular drinking water. In each experiment, a treated-to-control ratio was calculated ( ${ }^{*} p<0.05$ Ang I| 1000 + vehicle versus control + vehicle; $\$ p \leq 0.05$ Ang II 1000 + Hyd versus Ang II 1000 + vehicle, by two-way ANOVA with Tukey post-test, $n=3-8$ ). Representative micrographs of Iba-1 and GFAP immunostaining in CA3 area of hippocampus are shown (scale $50 \mu \mathrm{m})$

did not present elevations in peripheral plasma cytokines, neither after 1 week nor after 2 weeks perfusion (Fig. 6a, b and Additional file 2: Figure S1E, $n=6-8$ ).

Despite the robust systemic pro-inflammatory effect seen with hypertensive Ang II, ELISA analysis did not detect an elevation of these cytokines in the whole brain with any of the doses (Fig. 6c, d, $n=6-8$ ). This was not due to a lack of detection capacity of our method as mice receiving a single systemic LPS injection showed significant increases in the production of TNF- $\alpha$ (1.4-fold, $p=$ $0.047)$ and of IL-6 (26-fold, $p<0.0001)$ compared to controls (Fig. 6c, d, $n=7$ ). Even with longer perfusion times, no changes in TNF- $\alpha$ production in the whole brain were detected with infusion of Ang II $200 \mathrm{ng} / \mathrm{kg} / \mathrm{min}$ for 2 weeks (Additional file 2: Figure S1F, $n=6-8$ ).

Table 3 Effect of hydralazine treatment on hypertension induced by Ang $\|$

\begin{tabular}{lllll}
\hline & Control & Ang $\|$ & Control + Hyd & Ang $\|+$ Hyd \\
\hline SBP day 0 & $127.0 \pm 4.1$ & $127.6 \pm 2.5$ & $119.4 \pm 3.5$ & $120.1 \pm 3.6$ \\
SBP day 4 & $130.7 \pm 3.7$ & $165.4 \pm 4.6^{\S}$ & $118.9 \pm 3.5$ & $131.0 \pm 4.0^{\natural}$ \\
SBP day 7 & $125.4 \pm 3.8$ & $171.4 \pm 5.3^{\S}$ & $115.2 \pm 3.7$ & $122.7 \pm 2.6^{\sharp}$ \\
\hline
\end{tabular}

Systolic blood pressure (SBP, $\mathrm{mmHg}$ ) was assessed via the tail-cuff method. Mice were implanted with osmotic minipumps containing Ang II $1000 \mathrm{ng} / \mathrm{kg} /$ min or $0.9 \% \mathrm{NaCl}$ (referred as control). Hydralazine (Hyd, $150 \mathrm{mg} / \mathrm{L}$ ) was administered in the drinking water and started 3 days before minipump implantation. Data is expressed as mean \pm SEM, $n=11$-20/group; two-way ANOVA with Tukey post-test. Main effect of time $F(2,191)=11.58, p<0.0001$; main effect of treatment $F(3,191)=49.42, p<0.0001$; interaction $F(6$, 191) $=8.772, p<0.0001$

${ }^{5} p<0.0001$ Ang II day 4 and day 7 versus day 0 and versus control; $" ~ p<0.0001$ Ang II + Hyd versus Ang II on day 4 and day 7
Effect of Ang II on TNF-a production in the hippocampus We next considered whether the apparent absence of increased cytokine production in the brain of mice chronically infused with Ang II was due to the presence of a specific regional change, which was diluted by analysis of the whole brain. We decided to examine TNF- $\alpha$ in more detail rather than IL- 6 , based on previous evidence that hypothalamic microglia isolated from Ang II-treated mice exhibit a significant increase in TNF- $\alpha$ expression and a milder increase in IL-6 $[17,18]$. In line with the proposed hypothesis, ELISA analysis of hippocampal homogenates revealed a significant increase in TNF- $\alpha$ levels in mice infused with Ang II $1000 \mathrm{ng} / \mathrm{kg} / \mathrm{min}$ compared to controls ( $p$ $=0.040$, Fig. 6e, $n=6-9$ ). Supporting the effects of blood pressure on cerebral inflammation, hydralazine treatment prevented the increase in hippocampal TNF- $\alpha$ production triggered by hypertensive Ang II $(p=0.037$, Fig. 6e), with a similar trend in the periphery (Fig. 6f, $n=6-9$ ).

We further examined the association between hippocampal TNF- $\alpha$ and systolic blood pressure via correlation analysis. While a significant positive association was found between the concentration of TNF- $\alpha$ measured in plasma and blood pressure ( $r 0.658, p=0.017)$, Spearman analysis did not reveal a significant correlation between these two parameters when TNF- $\alpha$ was assessed in the brain ( $r 0.456 p=0.102)$, suggesting a non-linear relationship between blood pressure and cerebral inflammation. 


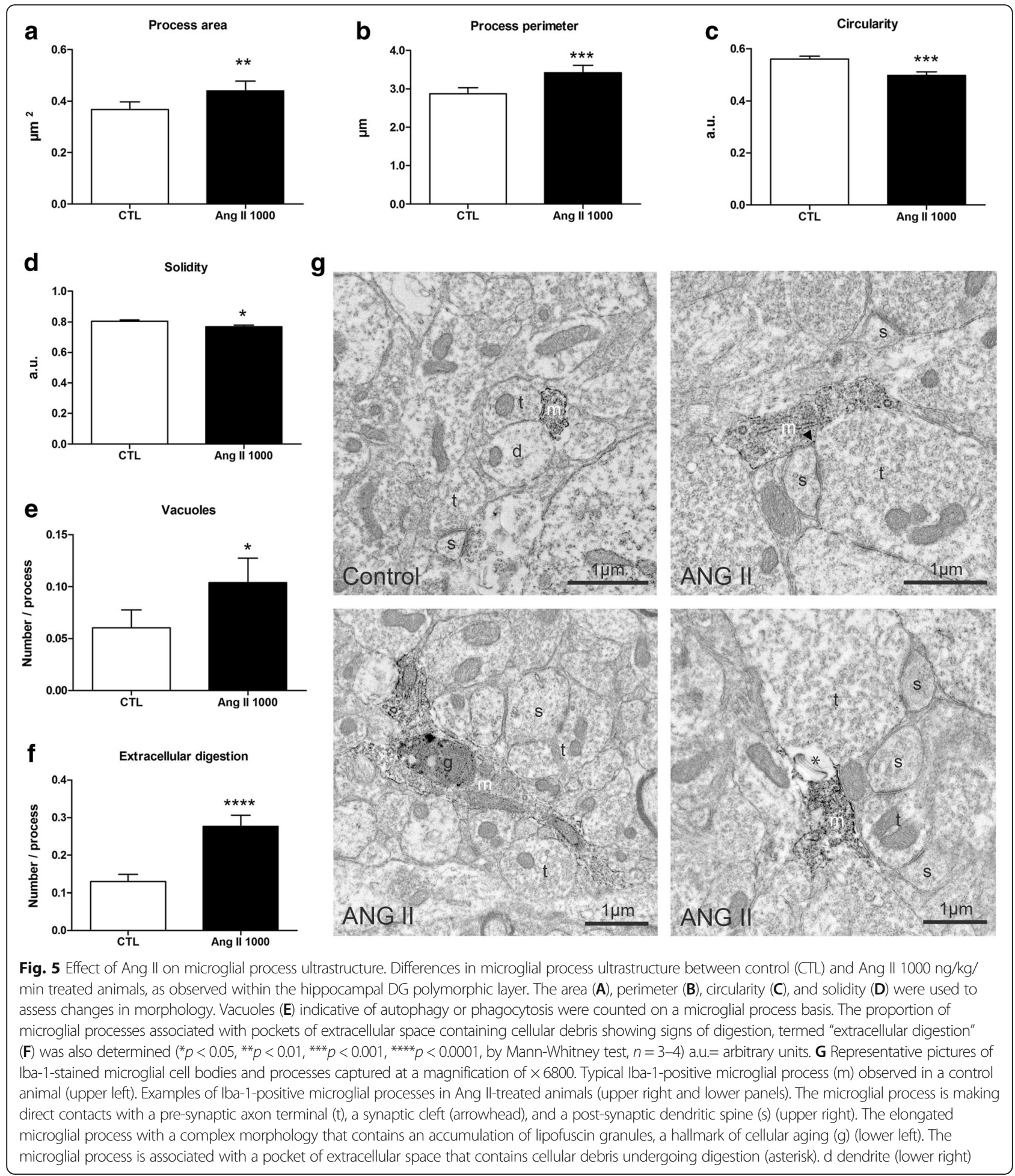

\section{Discussion}

This study presents several novel findings. First, it provides new knowledge on specific brain regions involved in Ang II-induced inflammation beyond the PVN, by showing increased TNF- $\alpha$ production, elevated GFAP expression, and microgliosis in the hippocampus.
Second, it presents a thorough quantitative characterization of hippocampal microglia morphology achieved via EM, providing a better understanding of their functional activation state in relation to hypertension. Third, it reveals that both increased blood pressure and Ang II concentrations are important 

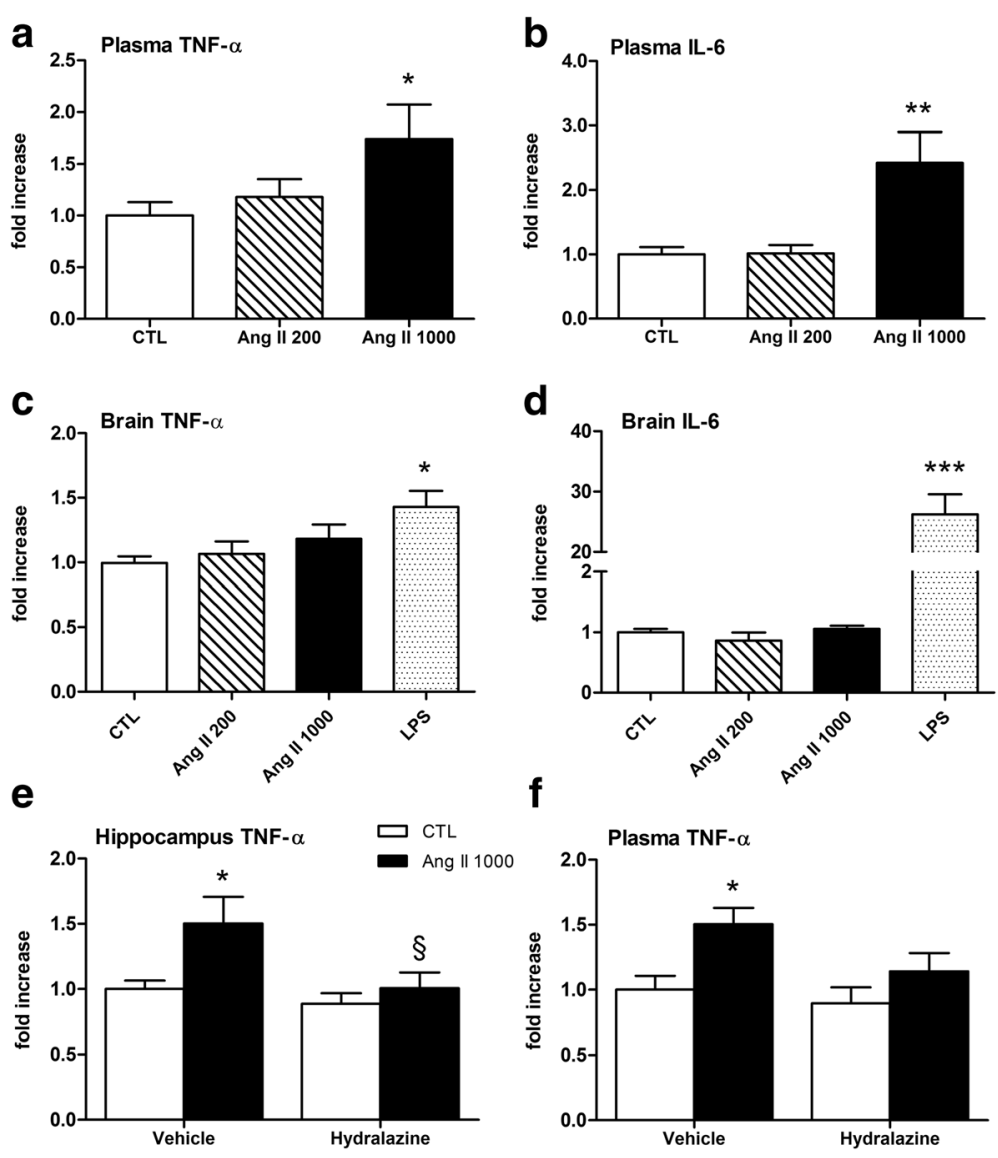

Fig. 6 Effect of Ang II on cerebral and systemic cytokine production. ELISA analysis of TNF-a and IL-6 in plasma (a, b) and whole brain homogenates (c, d) after 1 week perfusion of Ang II 200, $1000 \mathrm{ng} / \mathrm{kg} / \mathrm{min}$ or $0.9 \%$ saline (CTL). LPS (2 mg/kg) was injected i.p. and mice were sacrificed $3 \mathrm{~h}$ after. A treated-to-control ratio was calculated. ${ }^{*} p<0.05,{ }^{* *} p<0.01,{ }^{* * *} p<0.001$ versus control, by one-way ANOVA with Tukey post-test, $\left.n=6-8\right)$. e, $\mathbf{f}$ ELISA analysis in hippocampus (e) and plasma (f) of mice receiving Ang II $1000 \mathrm{ng} / \mathrm{kg} / \mathrm{min}$ or $0.9 \%$ saline (CTL) for 1 week. Hydralazine (150 mg/L) was administered in the drinking water and started 3 days before minipump implantation. Animals in the vehicle group received regular drinking water. Results are expressed a treated-to-control ratio. $\left({ }^{*} p<0.05\right.$ Ang $\|+$ vehicle versus control + vehicle, $\$ p<0.05$ Ang $\|+$ Hyd versus Ang $\|+$ vehicle by two-way ANOVA with Tukey post-test, $n=6-9)$

contributors to hippocampal inflammation induced by systemic Ang II.

Ang II, the main effector of the renin-angiotensin system, is a circulating peptide hormone and a potent vasoconstrictor that exerts key roles in the regulation of blood pressure and the development of hypertension [24]. The brain also has its own intrinsic reninangiotensin system from where Ang II is produced [25-28]. In rodents and humans, Ang II binding sites are expressed widely throughout the brain including the cerebral vasculature and circumventricular organs (CVO), where they have access to systemic Ang II [27, 29, 30]. Within the brain parenchyma, angiotensin II type I (AT1) receptors are highly expressed in neurons among specific brain regions involved in autonomic and cardiovascular regulation and, although in lower levels, in other areas including the cerebral cortex, hippocampus, basal ganglia, and cerebellum $[27,29,30]$.
Whether systemic Ang II and increased blood pressure contributed to cerebral inflammation beyond the cerebral vasculature and PVN was not clear before this study. Therefore, we delivered pressive and subpressive doses of Ang II and used phenylephrine or hydralazine, which modulate blood pressure independently of the renin angiotensin system (phenylephrine increases blood pressure via $\alpha-1$ adrenergic receptors, and hydralazine lowers blood pressure by relaxing vascular smooth muscle). With these approaches, our results show that circulating Ang II leads to hippocampal inflammation and cerebral gliosis in a dose-dependent manner and that increased blood pressure is an important contributor to the brain proinflammatory effects of Ang II in mice.

Is blood pressure elevation alone sufficient? With administration of phenylephrine, we did not observe an increase in Iba-1, as we have seen with the highest hypertensive dose of Ang II, even though the dose of 
phenylephrine was ten times higher than that of Ang II $(19 \mu \mathrm{g} / \mathrm{kg} / \mathrm{min}$ versus $1900 \mathrm{ng} / \mathrm{kg} / \mathrm{min})$. In addition, analysis showed a non-linear correlation between hippocampal TNF- $\alpha$ and blood pressure, suggesting that other factors could modulate the association between these parameters. For example, the breakdown of the bloodbrain barrier (BBB) induced by Ang II may be involved in the inflammatory process [31, 32]. Indeed, a study from Marvar showed that Ang II is critical for BBB damage, independently of blood pressure [31]. The effects of Ang II are also highlighted in this study by the fact that hippocampal Iba-1 levels rose with increasing concentrations of Ang II, while the increase in blood pressure produced by these hypertensive doses was similar. Likewise, increasing subpressive Ang II (200 $\mathrm{ng} / \mathrm{kg} / \mathrm{min})$ infusion duration to 14 days resulted in a significant increase in hippocampal CD68 mRNA, with a similar trend for Iba-1, without changes of GFAP or TNF- $\alpha$. These results emphasize the importance of Ang II actions and also suggest that a certain threshold of blood pressure may be required for the full expression of cerebral inflammation.

Despite bypassing the renin-angiotensin system, we observed a significant increase in GFAP expression in the hippocampus with phenylephrine treatment. This vulnerability of astrocytes is not surprising considering their anatomical proximity to cerebral blood vessels as part of the neurovascular unit [33], being close targets of the pressor stress suffered by the vasculature in hypertension. Indeed, it is known that astrocytes can act as "sensors" to vascular damage, by expressing ion channels sensitive to shear stress, such as TRPV4 (transient receptor potential vanilloid subtype 4) [34], which when activated lead to the development of astrogliosis [35].

Beyond our study, a critical role for Ang II on cerebral inflammation is supported by a previous work showing that inhibition of AT1 receptors with candesartan, a centrally acting angiotensin receptor blocker, leads to reductions in brain inflammation induced by LPS or stroke in normotensive rats [36, 37]. At the same time, our results on blood pressure complement the findings of Marvar and colleagues who used a similar approach with hydralazine to demonstrate that the pressor effects of Ang II are critical for the activation of circulating $\mathrm{T}$ lymphocytes and the expression of vascular inflammation in mice [31]. Interestingly, there is also evidence that hydralazine attenuates cardiac fibrosis and inflammation induced by pressive Ang II in mice, suggesting that blood pressure is also a key contributor to the expression of inflammation in other end organs affected by hypertension besides the brain [38].

With respect to hydralazine, there have been reports indicating it exhibits antioxidant properties beyond its well-recognized antihypertensive effect, including scavenger actions on peroxynitrite and oxygen radicals [39-
41]. Although it can be argued that attenuation of oxidative stress by this peripheral vasodilator could have helped diminish the cerebral inflammation caused by hypertensive Ang II, some considerations reaffirm its main mechanism of action through blood pressure reduction. First, the range of hydralazine doses with antioxidant properties previously reported was much higher than the dose used in this study ( $\geq 250$ versus $150 \mathrm{mg} / \mathrm{L}$, respectively). Second, although low hydralazine doses (similar or lower than this study) demonstrated ROS scavenging actions in vitro (reductions of oxidative radicals by $25 \%$ ), this effect was significantly lower compared to classical antioxidants such as ascorbic acid, which reduced oxygen radical production by $80 \%$ [39]. Third, in the discussed studies, the antioxidant actions of hydralazine have been evaluated in vitro in peritoneal macrophages, cultured smooth muscle cells, and isolated vessels, or ex vivo in isolated rabbit aortas. Therefore, to the best of our knowledge, the cerebral antioxidant actions of hydralazine remain to be demonstrated.

Previous studies examining the cerebral proinflammatory effects of pressive Ang II focused on the $\mathrm{PVN}$, a region of the hypothalamus involved in the sympathetic control of blood pressure [15]. These studies showed changes in microglial morphology (enlarged soma, process retraction) and increased production of pro-inflammatory cytokines (IL-1 $\beta$, IL-6, and TNF- $\alpha$ ) [16-18]. Our results confirm that pressive Ang II leads to cerebral gliosis and extends this finding to another brain region, namely the hippocampus. Our work also complements the study of Toth and colleagues who demonstrated that the hippocampal expression of the chemokines MCP-1 (CCL2) and IP-10 (CXCL10) is increased in young mice (3 months) receiving pressive doses of Ang II (1000 ng/ $\mathrm{kg} / \mathrm{min}, 28$ days), a response that is exacerbated by aging ( 24 months), where upregulation of CD68 and TNF- $\alpha$ then became evident [42].

Besides an upregulation of TNF- $\alpha$ and astrogliosis, we report significant morphological changes of microglia in the hippocampus of mice infused with pressive Ang II, as detected by immuno-EM. Changes in microglial morphology are informative of their functional activation state in response to stimuli or injury. In this study, we labeled microglia with Iba-1, which is a well-recognized marker specifically expressed by resident microglia and macrophages [43, 44]. We report significant changes in quantitative shape and functional descriptors including increases in microglial process area and perimeter, reductions in circularity and solidity, and a greater number of vacuoles and increased extracellular digestion.

The increase in process area and perimeter would indicate that they are larger in the presence of Ang II, reflecting process thickening and therefore increased metabolic or lysosomal activity. This is also supported 
by the finding of reduced solidity and thus of a more ruffled morphology, which could be a sign of increased process motility reflecting their capacity to reorient towards sites of injury [45]. Furthermore, the changes in vacuoles and increased extracellular digestion suggest an involvement of microglia in synaptic remodeling in the presence of Ang II. This is supported by the EM micrographs showing microglial processes with complex morphologies making contacts with pre-synaptic axon terminals, synaptic clefts, and post-synaptic dendritic spines and containing cellular debris being degraded. A seminal study recently showed that the physiological functions of microglia that prune excess synapses during development are aberrantly activated in Alzheimer's disease animal models, contributing to synaptic loss, which is a strong correlate of cognitive decline [46]. It is therefore possible that microglia in the presence of Ang II undergo phenotypic changes that lead to inflammation, synaptic pruning, and ultimately cognitive impairments. Indeed, these specific changes in the hippocampus are in line with our earlier findings that pressive Ang II leads to cognitive dysfunctions in tasks that are dependent on this region [22]. They are also consistent with a recent study examining the impact of Ang II (1000 ng/kg/min, 28 days perfusion) on synaptic plasticity in mice, showing that systemic Ang II leads to reductions in hippocampal long-term potentiation, decreased density of hippocampal synapses, and reduced expression of key genes involved in synaptic plasticity, such as Bdnf and Homer1 [47]. We could thus speculate that the development of hippocampal inflammation and synaptic dysfunction is a mechanistic link between early hypertension and the brain deficits that lead to neuronal injury and dementia in late-life [19-21].

It is interesting that such significant and specific changes in hippocampal microglia morphology were detected in the absence of increased expression of Iba- 1 or CD68 in this region. These results highlight the sensitivity of immuno-EM ultrastructural studies to reveal alterations in microglia morphological dynamics that may otherwise appear "normal" when examined by protein or gene expression analysis. With respect to other regions, the increase in Iba-1 in the whole brain in response to pressive Ang II could be a signal of increased microglial numbers or phenotypic alterations taking place outside the hippocampus (e.g., the PVN, as previously shown) or even in the white matter, an interesting hypothesis warranting future investigations.

In addition to maintaining brain homeostasis, microglia undergo phenotypic transformation upon tissue injury, or in response to Ang II, leading to the secretion of inflammatory and oxidative molecules that contribute to neurodegeneration [48]. A recent study demonstrated that isolated hypothalamic microglia actually respond to
Ang II through AT1 and TLR4 receptors, the latter which is required for the expression of oxidative damage induced by Ang II in mice [49]. Although the role of other cells including neurons and astrocytes cannot be discarded, the ultrastructural morphological changes along with the increased hippocampal TNF- $\alpha$ production suggest the emergence of a pro-inflammatory microglial phenotype in mice with chronic Ang II administration. This is supported by Shen and colleagues who showed that the increase in hypothalamic TNF- $\alpha$ that results from in vivo Ang II administration returned to normal levels when microglia were depleted from the brain [17].

Besides affecting microglia, our finding of increased hippocampal GFAP expression in response to pressive Ang II indicates that astrocyte activation is also involved in Ang II-induced neuroinflammation. Indeed, in a very comprehensive study, Stern and colleagues recently showed that astrocytes are critical and direct cellular mediators of Ang II actions on PVN neurons, leading to increased sympathetic outflow and to increased blood pressure [50].

Therefore, it is likely that the cerebral inflammation induced by Ang II involves multiple pathways and cellular players, including but not limited to (i) the direct effects of circulating Ang II on AT1 receptors in cerebral vessels [51]; (ii) the damage to the BBB [32], which could facilitate the entry of Ang II to brain regions beyond the CVO network (i.e., the hippocampus); (iii) the consequent effects on microglia and astrocytes, leading to the expression of pro-inflammatory cytokines within the brain; and (iv) the entry of activated immune cells from the periphery.

The findings of our study must be considered within its limitations. One lesson learned from our work is that microglia morphology analysis via EM is able to detect subtler and even more informative changes than immunofluorescence, as seen by the lack of Iba-1 increase with the dose of $1000 \mathrm{ng} / \mathrm{kg} /$ min Ang II in parallel with significant changes in the morphology of microglia. In this regard, although Iba1 levels in phenylephrine-treated animals were comparable to controls, we cannot discard the possibility that phenylephrine could have affected microglia morphology in this group. It would be interesting to examine whether metabolic changes in microglia differ upon Ang II or phenylephrine treatment despite similar effects on blood pressure. Also, our study examined only male mice and potential sex differences in the response to the pressive and inflammatory effects of Ang II cannot be discarded. Despite these considerations, this work broadens our understanding of the in vivo effects of Ang II actions in relation to hypertension and its impact on brain inflammation. 


\section{Conclusions}

Our results indicate that the cerebral pro-inflammatory effects of pressive Ang II involve changes in microglial morphology, as well as increases in cytokine production and GFAP expression in a region of the brain critical for memory. EM analysis revealed phenotypic alterations in microglia consistent with an active metabolic state, which could be involved in synaptic remodeling, in the absence of increases in Iba-1 or CD68 expression. This emphasizes the value of immuno-EM to reveal alterations in cerebral gliosis upon tissue injury. The findings of this study also indicate that increased blood pressure, in addition to Ang II itself, is an important contributor to the development of cerebral inflammation. Taken together, these results open the door for future investigations on the mechanisms underlying the induction of cerebral inflammation by hypertension, leading to new questions such as the following: What is the threshold of blood pressure necessary to induce cerebral inflammation? Which parameters influence this threshold? Can antihypertensive treatments reverse this inflammation? Answers to these questions may provide great advancements for a better understanding of the link between hypertension and cognitive decline as well as for the development of therapies against neurodegenerative diseases.

\section{Additional files}

Additional file 1: Supplementary Methods. (DOCX 59 kb)

Additional file 2: Figure S1. Effect of extended perfusion of subpressive Ang II on cerebral inflammation. Iba-1 (A) and GFAP (B) were examined by Western blotting in cerebral homogenates after 2 weeks systemic perfusion of Ang $\| 200 \mathrm{ng} / \mathrm{kg} / \mathrm{min}$ or $0.9 \%$ saline (CTL). Densitometry values of Iba-1 and GFAP were normalized to actin, and the results are expressed relative to the control group. Representative immunoblots are shown (two-tailed Student's $t$ test, $n=3$ ). CD68 mRNA (C) and GFAP mRNA (D) gene expression were analyzed by qRT-PCR in microdissected hippocampi after 2 weeks systemic perfusion of Ang II $200 \mathrm{ng} / \mathrm{kg} / \mathrm{min}$ or $0.9 \%$ saline (CTL). In each experiment, a treated-tocontrol ratio was calculated $\left({ }^{* *} p<0.01\right.$, Ang $\| 200$ versus control, by twotailed Student's $t$ test, $n=7$ ). ELISA analysis of TNF-a in plasma (E) and in whole brain homogenates (F) after 2 weeks perfusion of Ang II 200 ng/ $\mathrm{kg} / \mathrm{min}$ or $0.9 \%$ saline (CTL). A treated-to-control ratio was calculated (two-tailed Student's $t$ test, $n=6-8$ ). (TIFF $1442 \mathrm{~kb}$ )

\section{Abbreviations}

Ang II: Angiotensin II; AT1: Angiotensin II type l; a.u: arbitrary units; BBB: Blood-brain barrier; CA1: Cornu ammonis 1; CA3: Cornu ammonis 3; CVO: Circumventricular organs; DG: Dentate gyrus; DT: Diphtheria toxin; EM: Electron microscopy; GFAP: Glial fibrillary acidic protein; Hyd: Hydralazine; Iba-1: Ionized calcium-binding adaptor molecule 1; IL-1 $\beta$ : Interleukin-1 $\beta$; IL6: Interleukin 6; LPS: Lipopolysaccharides; PVN: Paraventricular nucleus; RFU: relative fluorescence intensity units; SBP: Systolic blood pressure; TNFa: Tumor necrosis factor-a

\section{Acknowledgements}

Not applicable

\section{Funding}

This study was supported by funds from the Canadian Institutes in Health Research (CIHR), the Fonds de recherche du Québec-Santé (FRQS), the
Heart and Stroke Foundation of Canada (HSFC), and the Canada Foundation for Innovation (CFI) awarded to HG. MET received support from the Natural Sciences and Engineering Research Council of Canada (NSERC) and is the recipient of a Tier 2 Canada Research Chair in Neuroimmune Plasticity in Health and Therapy. MFI was funded by a Bourse Postdoctorale from FRQS (2016-2018) and by the Herbert H. Jasper Postdoctoral Fellowship in Neurosciences (2016-2017) from the Groupe de Recherche sur le Système Nerveux Central (GRSNC), Université de Montréal. CAU received a Summer Trainee Award from the GRSNC. SD was the recipient of a PhD Scholarship from Heart and Stroke Foundation of Canada (2014-2015). AG was the recipient of an excellence scholarship from the Fédération des Caisses Desjardins. The funding bodies had no role in the design of the study or in the collection, analysis, and interpretation of data or in writing the manuscript.

\section{Availability of data and materials}

All data generated or analyzed during this study are included in this published article.

\section{Authors' contributions}

$\mathrm{HG}, \mathrm{DV}$, and MFI designed the study. $\mathrm{HG}, \mathrm{MFI}, \mathrm{DV}, \mathrm{MeB}, \mathrm{NH}, \mathrm{SD}, \mathrm{CAU}$, and MiB analyzed data and performed the minipump implantations, blood pressure assessments, and PCR, Western blotting, ELISA, and immunofluorescence experiments. $H G, A G, N V$, and MET analyzed data and performed immuno-EM. MFI, DV, MET, NV, and HG wrote the manuscript.

All authors read and approved the final manuscript.

\section{Ethics approval}

The study was approved by the Animal Care Committee of Université de Montréal, and all experiments were performed in accordance with the guidelines of the Canadian Council for Animal Care as well as conforming with the ARRIVE guidelines.

Consent for publication

Not applicable

Competing interests

The authors declare that they have no competing interests.

\section{Publisher's Note}

Springer Nature remains neutral with regard to jurisdictional claims in published maps and institutional affiliations.

\section{Author details}

1Department of Neurosciences, Université de Montréal, 2960 Chemin de la Tour, Montréal, Québec H3T 1J4, Canada. ${ }^{2}$ Groupe de recherche sur le système nerveux central (GRSNC), Université de Montréal, 2960 Chemin de la Tour, Montréal, Québec H3T 1J4, Canada. ${ }^{3}$ Department of Pharmacology and Physiology, Université de Montréal, Pavillon Roger-Gaudry, 2900 Boulevard Édouard-Montpetit, Montréal, Québec H3T 1J4, Canada. ${ }^{4}$ Axe Neurosciences, CRCHU de Québec-Université Laval, 2705 Boulevard Laurier, Québec, Québec G1V 4G2, Canada. ${ }^{5}$ Department of Molecular Medicine, Université Laval, 1050, Avenue de la Médecine, Québec, Québec G1V 0A6, Canada. ${ }^{6}$ Centre de recherche de I'Institut universitaire de gériatrie de Montréal, 545 Queen Mary Rd, Montréal, Québec H3W 1W6, Canada.

Received: 15 January 2018 Accepted: 5 February 2018

Published online: 28 February 2018

\section{References}

1. Rigaud AS, Forette B. Hypertension in older adults. J Gerontol A Biol Sci Med Sci. 2001;56:M217-25.

2. Lawes CM, Bennett DA, Feigin VL, Rodgers A. Blood pressure and stroke: an overview of published reviews. Stroke. 2004;35:1024.

3. Qiu C, Winblad B, Fratiglioni L. The age-dependent relation of blood pressure to cognitive function and dementia. Lancet Neurol. 2005;4: 487-99.

4. Caillon A, Schiffrin EL. Role of inflammation and immunity in hypertension: recent epidemiological, laboratory, and clinical evidence. Curr Hypertens Rep. 2016;18:21. 
5. Seaberg EC, Munoz A, Lu M, Detels R, Margolick JB, Riddler SA, Williams CM, Phair JP, Multicenter ACS. Association between highly active antiretroviral therapy and hypertension in a large cohort of men followed from 1984 to 2003. AIDS. 2005:19:953-60

6. Youn JC, Yu HT, Lim BJ, Koh MJ, Lee J, Chang DY, Choi YS, Lee SH, Kang SM, Jang $Y$, et al. Immunosenescent CD8+ T cells and C-X-C chemokine receptor type 3 chemokines are increased in human hypertension. Hypertension. 2013;62:126-33.

7. Chae CU, Lee RT, Rifai N, Ridker PM. Blood pressure and inflammation in apparently healthy men. Hypertension. 2001;38:399-403.

8. Guzik TJ, Hoch NE, Brown KA, McCann LA, Rahman A, Dikalov S, Goronzy J, Weyand C, Harrison DG. Role of the T cell in the genesis of angiotensin II induced hypertension and vascular dysfunction. J Exp Med. 2007;204: 2449-60.

9. Svendsen UG. Evidence for an initial, thymus independent and a chronic, thymus dependent phase of DOCA and salt hypertension in mice. Acta Pathol Microbiol Scand A. 1976;84:523-8.

10. Olsen F. Transfer of arterial hypertension by splenic cells from DOCA-salt hypertensive and renal hypertensive rats to normotensive recipients. Acta Pathol Microbiol Scand C. 1980;88:1-5.

11. Rodriguez-Iturbe B, Pons H, Quiroz Y, Gordon K, Rincon J, Chavez M, Parra G, Herrera-Acosta J, Gomez-Garre D, Largo R, et al. Mycophenolate mofetil prevents salt-sensitive hypertension resulting from angiotensin II exposure. Kidney Int. 2001;59:2222-32.

12. De Ciuceis C, Amiri F, Brassard P, Endemann DH, Touyz RM, Schiffrin EL. Reduced vascular remodeling, endothelial dysfunction, and oxidative stress in resistance arteries of angiotensin II-infused macrophage colonystimulating factor-deficient mice: evidence for a role in inflammation in angiotensin-induced vascular injury. Arterioscler Thromb Vasc Biol. 2005;25: 2106-13.

13. Barhoumi T, Kasal DA, Li MW, Shbat L, Laurant $P$, Neves MF, Paradis $P$, Schiffrin EL. T regulatory lymphocytes prevent angiotensin II-induced hypertension and vascular injury. Hypertension. 2011;57:469-76.

14. Mian MO, Barhoumi T, Briet M, Paradis P, Schiffrin EL. Deficiency of Tregulatory cells exaggerates angiotensin $\|$-induced microvascular injury by enhancing immune responses. J Hypertens. 2016;34:97-108.

15. Kannan H, Hayashida $Y$, Yamashita H. Increase in sympathetic outflow by paraventricular nucleus stimulation in awake rats. Am J Phys. 1989;256: R1325-30.

16. Shi P, Diez-Freire C, Jun JY, Qi Y, Katovich MJ, Li Q, Sriramula S, Francis J, Sumners C, Raizada MK. Brain microglial cytokines in neurogenic hypertension. Hypertension. 2010;56:297-303.

17. Shen XZ, Li Y, Li L, Shah KH, Bernstein KE, Lyden P, Shi P. Microglia participate in neurogenic regulation of hypertension. Hypertension. 2015;66:309-16.

18. Li Y, Shen XZ, Li L, Zhao TV, Bernstein KE, Johnson AK, Lyden P, Fang J, Shi $P$. Brain transforming growth factor-beta resists hypertension via regulating microglial activation. Stroke. 2017:48:2557-64.

19. Launer LJ, Masaki K, Petrovitch H, Foley D, Havlik RJ. The association between midlife blood pressure levels and late-life cognitive function. The Honolulu-Asia aging study. JAMA. 1995;274:1846-51.

20. Launer LJ, Ross GW, Petrovitch H, Masaki K, Foley D, White LR, Havlik RJ. Midlife blood pressure and dementia: the Honolulu-Asia aging study. Neurobiol Aging. 2000;21:49-55.

21. Skoog I, Lernfelt B, Landahl S, Palmertz B, Andreasson LA, Nilsson L, Persson G, Oden A, Svanborg A. 15-year longitudinal study of blood pressure and dementia. Lancet. 1996;347:1141-5.

22. Duchemin S, Belanger E, Wu R, Ferland G, Girouard H. Chronic perfusion of angiotensin II causes cognitive dysfunctions and anxiety in mice. Physiol Behav. 2013;109:63-8.

23. Sadekova N, lulita MF, Vallerand D, Muhire G, Bourmoum M, Claing A, Girouard $\mathrm{H}$. Arterial stiffness induced by carotid calcification leads to cerebral gliosis mediated by oxidative stress. J Hypertens. 2018;36:286-298.

24. Hall JE. Control of blood pressure by the renin-angiotensin-aldosterone system. Clin Cardiol. 1991;14:IV6-21. discussion IV51-25

25. Dzau VJ, Ingelfinger J, Pratt RE, Ellison KE. Identification of renin and angiotensinogen messenger RNA sequences in mouse and rat brains. Hypertension. 1986;8:544-8.

26. Changaris DG, Keil LC, Severs WB. Angiotensin II immunohistochemistry of the rat brain. Neuroendocrinology. 1978;25:257-74.

27. Sirett NE, McLean AS, Bray JJ, Hubbard JI. Distribution of angiotensin II receptors in rat brain. Brain Res. 1977;122:299-312.
28. Fischer-Ferraro C, Nahmod VE, Goldstein DJ, Finkielman S. Angiotensin and renin in rat and dog brain. J Exp Med. 1971;133:353-61.

29. MacGregor DP, Murone C, Song K, Allen AM, Paxinos G, Mendelsohn FA. Angiotensin II receptor subtypes in the human central nervous system. Brain Res. 1995;675:231-40.

30. Barnes JM, Steward LJ, Barber PC, Barnes NM. Identification and characterisation of angiotensin II receptor subtypes in human brain. Eur J Pharmacol. 1993;230:251-8.

31. Marvar PJ, Thabet SR, Guzik TJ, Lob HE, McCann LA, Weyand C, Gordon FJ, Harrison DG. Central and peripheral mechanisms of T-lymphocyte activation and vascular inflammation produced by angiotensin II-induced hypertension. Circ Res. 2010;107:263-70.

32. Faraco G, Sugiyama Y, Lane D, Garcia-Bonilla L, Chang H, Santisteban MM, Racchumi G, Murphy M, Van Rooijen N, Anrather J, ladecola C. Perivascular macrophages mediate the neurovascular and cognitive dysfunction associated with hypertension. J Clin Invest. 2016;126:4674-89.

33. Sofroniew MV, Vinters HV. Astrocytes: biology and pathology. Acta Neuropathol. 2010;119:7-35.

34. Filosa JA, Yao X, Rath G. TRPV4 and the regulation of vascular tone J Cardiovasc Pharmacol. 2013;61:113-9.

35. Butenko O, Dzamba D, Benesova J, Honsa P, Benfenati V, Rusnakova V Ferroni S, Anderova M. The increased activity of TRPV4 channel in the astrocytes of the adult rat hippocampus after cerebral hypoxia/ischemia. PLoS One. 2012;7:e39959.

36. Benicky J, Sanchez-Lemus E, Honda M, Pang T, Orecna M, Wang J, Leng Y, Chuang DM, Saavedra JM. Angiotensin II AT1 receptor blockade ameliorates brain inflammation. Neuropsychopharmacology. 2011;36:857-70.

37. Schmerbach K, Schefe JH, Krikov M, Muller S, Villringer A, Kintscher U, Unger $\mathrm{T}$, Thoene-Reineke C. Comparison between single and combined treatment with candesartan and pioglitazone following transient focal ischemia in rat brain. Brain Res. 2008;1208:225-33.

38. Qi G, Jia L, Li Y, Bian Y, Cheng J, Li H, Xiao C, Du J. Angiotensin II infusioninduced inflammation, monocytic fibroblast precursor infiltration, and cardiac fibrosis are pressure dependent. Cardiovasc Toxicol. 2011;11:157-67.

39. Leiro JM, Alvarez E, Arranz JA, Cano E, Orallo F. Antioxidant activity and inhibitory effects of hydralazine on inducible NOS/COX-2 gene and protein expression in rat peritoneal macrophages. Int Immunopharmacol. 2004;4:163-77.

40. Munzel T, Kurz S, Rajagopalan S, Thoenes M, Berrington WR, Thompson JA, Freeman BA, Harrison DG. Hydralazine prevents nitroglycerin tolerance by inhibiting activation of a membrane-bound NADH oxidase. A new action for an old drug. J Clin Invest. 1996;98:1465-70.

41. Daiber A, Oelze M, Coldewey M, Kaiser K, Huth C, Schildknecht S, Bachschmid M, Nazirisadeh Y, Ullrich V, Mulsch A, et al. Hydralazine is a powerful inhibitor of peroxynitrite formation as a possible explanation for its beneficial effects on prognosis in patients with congestive heart failure. Biochem Biophys Res Commun. 2005;338:1865-74.

42. Toth P, Tucsek Z, Sosnowska D, Gautam T, Mitschelen M, Tarantini S, Deak F, Koller A, Sonntag WE, Csiszar A, Ungvari Z. Age-related autoregulatory dysfunction and cerebromicrovascular injury in mice with angiotensin II-induced hypertension. J Cereb Blood Flow Metab. 2013;33:1732-42.

43. Ahmed Z, Shaw G, Sharma VP, Yang C, McGowan E, Dickson DW. Actinbinding proteins coronin-1a and IBA-1 are effective microglial markers for immunohistochemistry. J Histochem Cytochem. 2007;55:687-700.

44. Kettenmann H, Hanisch UK, Noda M, Verkhratsky A. Physiology of microglia. Physiol Rev. 2011;91:461-553.

45. Ferretti MT, Bruno MA, Ducatenzeiler A, Klein WL, Cuello AC. Intracellular Abeta-oligomers and early inflammation in a model of Alzheimer's disease. Neurobiol Aging. 2012;33:1329-42.

46. Hong S, Beja-Glasser VF, Nfonoyim BM, Frouin A, Li S, Ramakrishnan S, Merry KM, Shi Q, Rosenthal A, Barres BA, et al. Complement and microglia mediate early synapse loss in Alzheimer mouse models. Science. 2016:352:712-6.

47. Tucsek Z, Noa Valcarcel-Ares M, Tarantini S, Yabluchanskiy A, Fulop G, Gautam T, Orock A, Csiszar A, Deak F, Ungvari Z. Hypertension-induced synapse loss and impairment in synaptic plasticity in the mouse hippocampus mimics the aging phenotype: implications for the pathogenesis of vascular cognitive impairment. GeroScience. 2017;39:385-406

48. Salter MW, Stevens B. Microglia emerge as central players in brain disease. Nat Med. 2017;23:1018-27. 
49. Biancardi VC, Stranahan AM, Krause EG, de Kloet AD, Stern JE. Cross talk between AT1 receptors and Toll-like receptor 4 in microglia contributes to angiotensin I-derived ROS production in the hypothalamic paraventricular nucleus. Am J Physiol Heart Circ Physiol. 2016;310:H404-15.

50. Stern JE, Son S, Biancardi VC, Zheng H, Sharma N, Patel KP. Astrocytes contribute to angiotensin II stimulation of hypothalamic neuronal activity and sympathetic outflow. Hypertension. 2016;68:1483-93.

51. Zhang M, Mao Y, Ramirez SH, Tuma RF, Chabrashvili T. Angiotensin II induced cerebral microvascular inflammation and increased blood-brain barrier permeability via oxidative stress. Neuroscience. 2010;171:852-8.

Submit your next manuscript to BioMed Central and we will help you at every step:

- We accept pre-submission inquiries

- Our selector tool helps you to find the most relevant journal

- We provide round the clock customer support

- Convenient online submission

- Thorough peer review

- Inclusion in PubMed and all major indexing services

- Maximum visibility for your research

Submit your manuscript at www.biomedcentral.com/submit
Biomed Central 